\title{
Bullous Lung disease
}

Gilbert Berdine, MD and Nopakoon Nantsupawat, MD

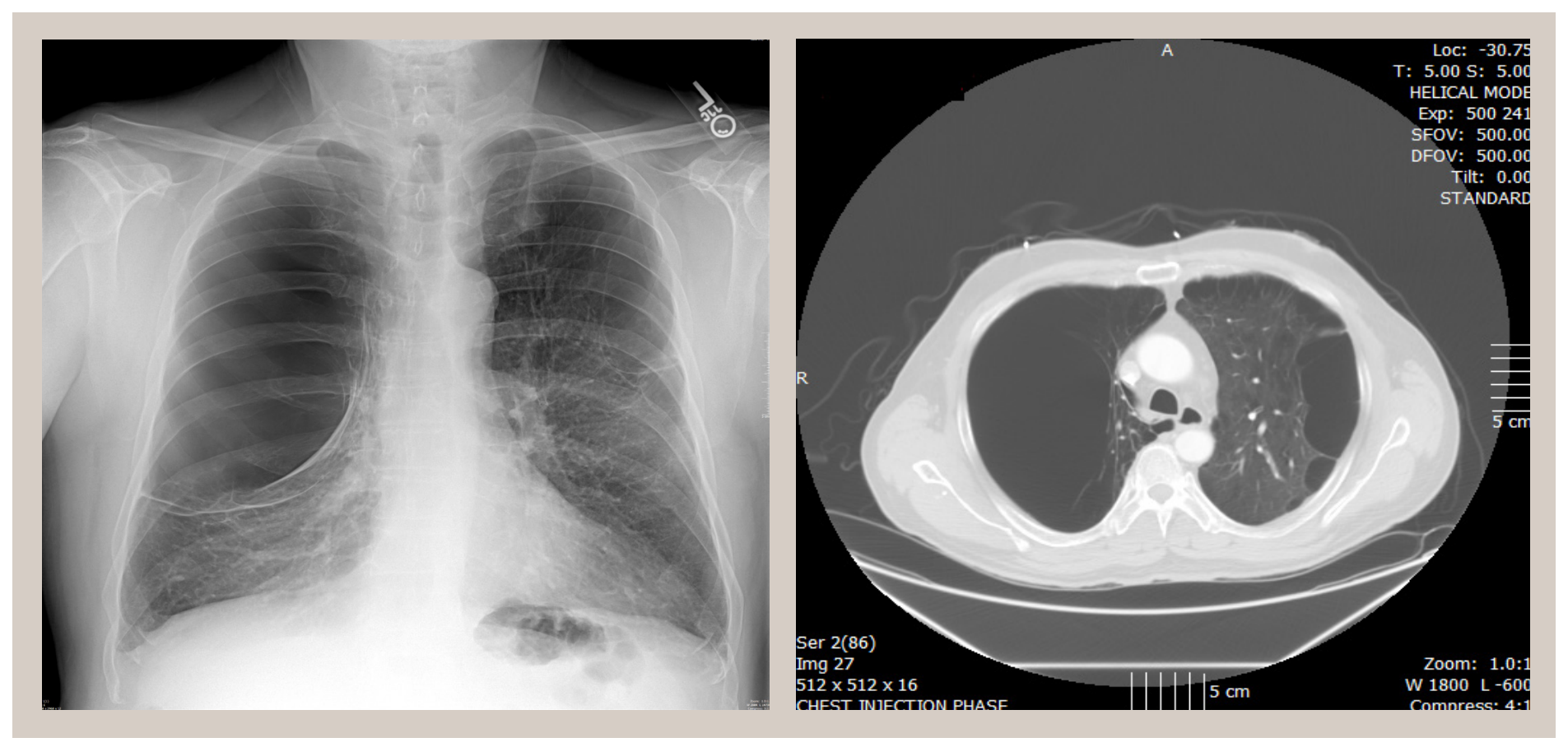

Figure 1 and 2 CXR and CT chest demonstrating large bullae in both lungs

A 52-year-old man was referred to Pulmonary Clinic for management of COPD. The patient has noted increasing dyspnea on exertion for the past 6-12 months. Approximately 6 months ago he passed out and was taken to the Emergency Room where he was given a diagnosis of COPD. He currently takes Symbicort, Atrovent, and albuterol. He noted no benefit from Symbicort, limited benefit from albuterol, and major improvement with Atrovent. He smokes 1 pack of cigarettes per day. He tried Chantix without success at smoking cessation.

On physical exam he had noacute distress. The patienthasdistantbreathsoundsandtherearenowheezes.

Corresponding author: Gilbert Berdine Contact Information: gilbert.berdine@ ttuhsc.edu

DOI: $10.12746 /$ swrccc2013.0102.020
Pulmonary function from 6 months ago included a FVC of 2.83 liters (55\%), a FEV1 of 1.47 liters $(35 \%)$, a FEV1/FVC of 0.518 , and no significant improvement following inhaled bronchodilator. TLC was $113 \%$ of predicted and RV was $222 \%$ of predicted. Diffusion capacity was $47 \%$ of predicted with only partial correction for alveolar volume (DL/VA $=66 \%$ ).

CT scan in the ER was negative for pulmonary embolism. Both CT and plain CXR demonstrate large bullae in both lungs with the right lung being much worse than the left (Figures 1 and 2). Based on these images, a V/Q scan was ordered to consider the patient for possible lung volume reduction surgery.

\section{COMMENT}

Bullae can develop in emphysematous lungs. Although bullae connect with the bronchial tree, air becomes trapped during the expiration and the bul- 


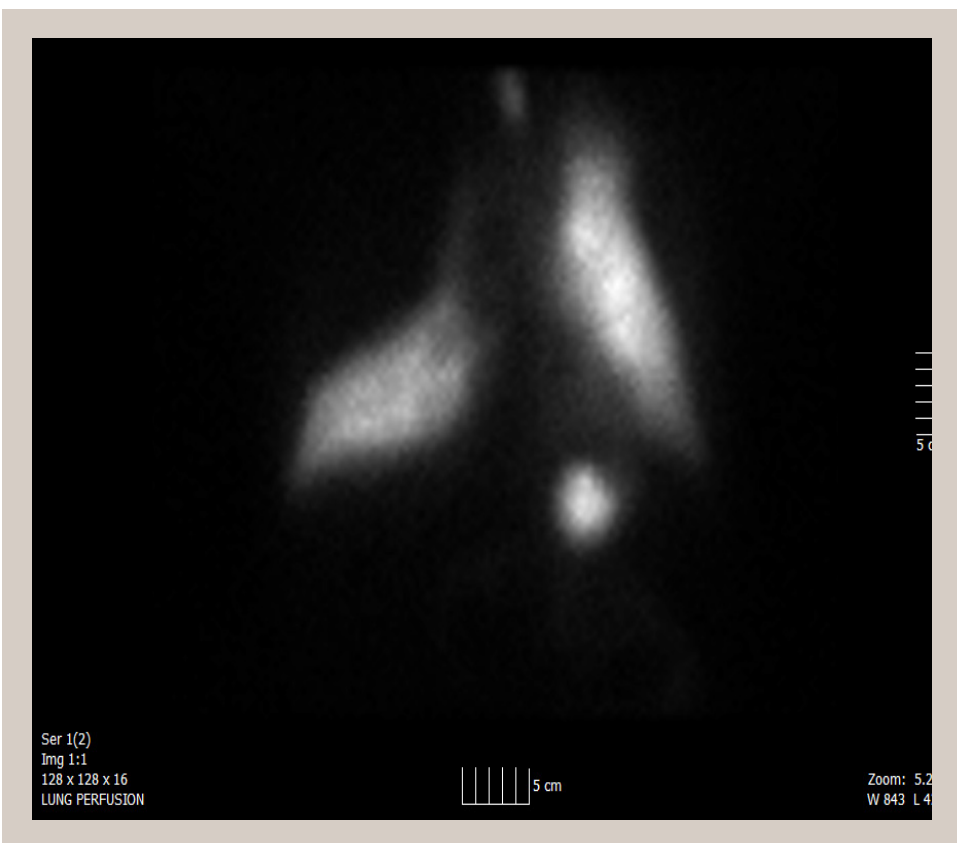

Figure $3 \mathrm{~V} / \mathrm{Q}$ Scan: Perfusion

lae increase in size. The adjacent lung often has more elastic recoil, and its retraction causes the bullae to increase in size. Cigarette smoking is associated with bullae in lungs; they also develop in other conditions, such as 1-antitrypsin deficiency and pulmonary sarcoidosis. Surgical management should be considered when the patients have respiratory distress with large bullae which occupy more than $30 \%$ of the hemithorax and compress the normal surrounding lung tissue. Surgical management is also needed when these patients have lung complications, such as infection or pneumothorax.

Received: $3 / 19 / 13$

Revised: $3 / 22 / 13$

Accepted: $3 / 25 / 13$

Published online: $4 / 16 / 13$

Reviewers: Kenneth Nugent MD

Conflict of Interest Disclosures: None

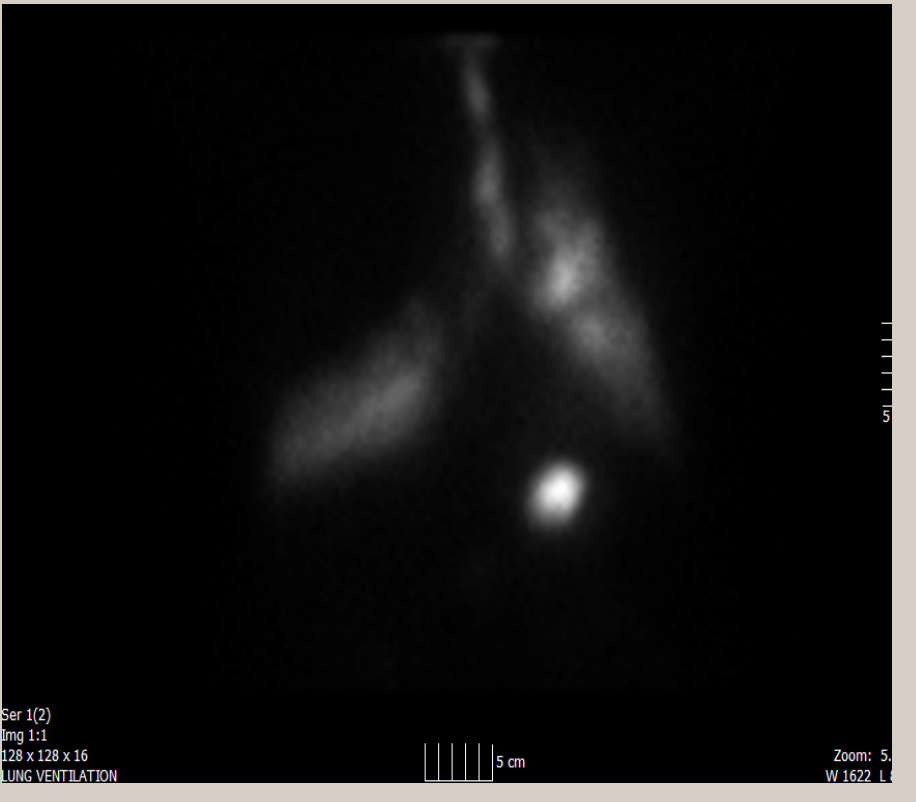

Figure $4 \mathrm{~V} / \mathrm{Q}$ Scan: Ventilation

\section{References}

1. Greenberg JA, Singhal S, Kaiser LR. Giant bullous lung disease: evaluation, selection, techniques, and outcomes. Chest Surg Clin N Am 2003; 13:631-49.

2. De Giacomo T, Rendina EA, Venuta F, et al. Bullectomy is comparable to lung volume reduction in patients with end-stage emphysema. Eur J Cardiothorac Surg 2002; 22:357-62.

3. Snider GL. Reduction pneumoplasty for giant bullous emphysema. Implications for surgical treatment of nonbullous emphysema. Chest 1996; 109:540-8.

4. Zar HJ, Cole RP. Bullous emphysema occurring in pulmonary sarcoidosis. Respiration 1995;62:290-3.

5. Kinnear WJM, Tattersfield A. Emphysematous bullae: surgery is best for large bullae and moderately impaired lung function. BMJ1990;300:208-9. 